\title{
An in-depth analysis of glycosylated haemoglobin level, body mass index and left ventricular diastolic dysfunction in patients with type 2 diabetes
}

Xin Zuo ${ }^{1}$, Xueting Liu', Runtian Chen ${ }^{1}$, Huiting Ou ${ }^{1}$, Jiabao Lai ${ }^{1}$, Youming Zhang ${ }^{2^{*}}$ (1) and Dewen Yan ${ }^{1 *}$

\begin{abstract}
Background: Glycosylated hemoglobin (HbA1c) has a detrimental impact on the myocardium with left ventricular (LV) diastolic dysfunction. Obesity is a risk factor of type 2 diabetes. To understand the relationships between $\mathrm{HbA1c}$, body mass index (BMI) and LV diastolic dysfunction, we performed this interaction analysis in patients with type 2 diabetes.

Methods: Total 925 type 2 diabetes patients were selected from the patients who were diagnosed and treated at the First Affiliated Hospital of Shenzhen University. Patients' BMl levels were defined as normal $\left(\mathrm{BMl}<24 \mathrm{~kg} / \mathrm{m}^{2}\right)$ and overweight /obese (BMI $\left.\geq 24 \mathrm{~kg} / \mathrm{m}^{2}\right)$. Patients' HbA1c levels were grouped as $\mathrm{HbA} 1 \mathrm{c} \geq 9 \%, 7 \% \leq \mathrm{HbA} 1 \mathrm{c}<9 \%$ and $\mathrm{HbA} 1 \mathrm{c}<7 \%$. Logistic regression, stratified, interaction analysis, multivariate Cox regression and curve fitting analysis were performed to investigate the correlations and interactions between $\mathrm{HbA1c}$ and BMI with LV diastolic dysfunction.

Results: The BMI levels were significantly associated with LV diastolic dysfunction in the patients with type 2 diabetes [adjusted model: $1.12(1.05,1.20), P=0.001]$. While HbA1c levels had association with LV diastolic dysfunction only in normal BMl group patients [adjusted model: $1.14(1.01,1.30), P=0.0394$ ] and curve correlation was observed. There was a significant interaction between $\mathrm{BMI}$ and $\mathrm{HbA} 1 \mathrm{c}$ to affect $\mathrm{LV}$ diastolic dysfunction $(P=0.0335)$. Cox regression model analysis showed that the risk of $\mathrm{LV}$ diastolic dysfunction was a $\mathrm{U}$ type correlation with $\mathrm{HbA1c}$ levels in the normal weight group and the turning point was $\mathrm{HbA1c}$ at $10 \%$. HbA1c level was not found to have a significant association with LV diastolic dysfunction in overweight/obese group.

Conclusions: In patients with type 2 diabetes, correlation between LV diastolic dysfunction and $\mathrm{HbA} 1 \mathrm{c}$ was interactively affected by BMI. Glycemic control is beneficial to the heart function in normal body weight patients. For overweight/obese patients, the risk of LV diastolic dysfunction was not determined by the HbA1c level, indicating it may be affected by other confounding factors.
\end{abstract}

Keywords: Type 2 diabetes, Left ventricular diastolic dysfunction, Glycosylated haemoglobin, Body mass index

\footnotetext{
* Correspondence: y.zhang@imperial.ac.uk; yandw963@126.com

${ }^{2}$ Genomic and Environmental Medicine Section, National Heart and Lung

Institute, Imperial College London, Dovehouse Street, London SW3 6LY, UK

${ }^{1}$ Department of Endocrinology, Xiangya-Shenzhen Endocrinology and

Metabolism Center, the First Affiliated Hospital of Shenzhen University,

Shenzhen, People's Republic of China
}

(c) The Author(s). 2019 Open Access This article is distributed under the terms of the Creative Commons Attribution 4.0 International License (http://creativecommons.org/licenses/by/4.0/), which permits unrestricted use, distribution, and reproduction in any medium, provided you give appropriate credit to the original author(s) and the source, provide a link to the Creative Commons license, and indicate if changes were made. The Creative Commons Public Domain Dedication waiver (http://creativecommons.org/publicdomain/zero/1.0/) applies to the data made available in this article, unless otherwise stated. 


\section{Background}

Diabetes is one of the most important health problems around the world in the twenty-first century [1]. The disease can cause damages in microvessels of multiple organs such as heart and kidney. Cardiovascular complications are the leading causes of death in patients with diabetes [2]. Diabetic cardiomyopathy (DCM) is generally considered to be the manifestation of microvascular disease in the heart [3]. The left ventricular (LV) diastolic dysfunction is the earliest functional change in DCM, and eventually progresses to heart failure with normal cardiac ejection fraction [4]. Hyperglycaemia in patients with diabetes can have much detrimental impacts on the myocardium form lipotoxicity, mitochondrial dysfunction, abnormal substrate metabolism and impaired calcium handling [5-7]. Glycosylated hemoglobin (HbA1c) can reflect the average level of glycemic control. The glycosylation occurs by the non-enzymatic reaction between glucose and $\mathrm{N}$-terminal end of the $\beta$-chain of hemoglobin [8]. An average of $1 \%$ reduction in mean $\mathrm{HbA1c}$ levels could reduce $37 \%$ microvascular complications [9]. Glycosylated hemoglobin plays an important role in the assessment of the occurrence, development and prognosis of diabetic cardiovascular complications. The high incidence of diastolic dysfunction was found in asymptomatic diabetes correlating with HbA1c levels in Indian patients [10].

Overweight and obesity have long been regarded as health risks associated with the type 2 diabetes [11]. Overweight and obesity itself not only can lead to left ventricular dilatation, hypertrophy, impaired relaxation and diastolic dysfunction; but also can cause aggravated insulin resistance, increase the difficulty of blood glucose control and increase the risk of cardiovascular disease. BMI can reflect the level of weight control. Until now, there was no report to focus on interaction analysis of body mass index (BMI), HbA1c levels and LV diastolic dysfunction in patients with type 2 diabetes in China; therefore we performed this investigation in a cohort of patients with type 2 diabetes in a region of South China.

\section{Methods}

\section{Population and data}

Total of 1440 patients with type 2 diabetes were diagnosed at the Endocrinology Department from January 2017 to October 2018 in the First Affiliated Hospital of Shenzhen University of Guangdong Province, South China. All information of the patients was recorded in a bioinformatics database called $\beta$-CVK ( $\beta$-function; $C$ cardiac; V-vascular; K-kidney). The database was established for evaluation of the functions of major organs such as pancreas islet, heart and kidney in patients with diabetes. Total 925 cases were selected in the current investigation with our inclusion criteria including: 1) $\mathrm{Pa}$ tients were diagnosed as type 2 diabetes according to
America Diabetes Association definition [12]; 2) Patients had complete data records such as age, height, weight, waist circumference, laboratory examinations and underwent a resting standard echocardiographic examination. Patients were excluded from the investigation if they met any of the following conditions: 1) Patients' ejection fraction (EF) was <50\%; 2) Patients had previous or current history of coronary artery diseases, congenital heart diseases, heart surgery and other heart diseases; 3 ) $\mathrm{BMI}<18.5 \mathrm{~kg} / \mathrm{m}^{2}$. 4) Patients had other serious diseases such as hematological tumors and uremia; 5) Patients had acute metabolic disorders including diabetic ketoacidosis and hyperosmolar coma. 6) Pregnant patients. 7) Patients with renal insufficiency (eGFR $<60 \mathrm{~mL} / \mathrm{min} / 1.73 \mathrm{~m}^{2}$ ).

The study was approved by the Ethics Committee of the First Affiliated Hospital of Shenzhen University, Shenzhen, China and was performed in accordance with the approved guidelines and regulations. Informed written consent was obtained from the parents of all subjects.

The selected patients were recorded with general information. BMI was divided into two different groups according to the Chinese expert consensus standards as normal weight group and overweight/obese group, using the thresholds of $\mathrm{BMI}<24 \mathrm{~kg} / \mathrm{m}^{2}$ and $\mathrm{BMI} \geq 24 \mathrm{~kg} / \mathrm{m}^{2}$, the standard was modified form the criteria applied by American College of Cardiology [13]. HbA1c level was detected by applying high performance liquid chromatography with the detection instrument I of BIO-RABD10 glycated hemoglobin detector; triglyceride (TG), total cholesterol (Cho), low density lipoprotein cholesterol (LDL-C), high Density lipoprotein cholesterol (HDL-C) and creatinine $(\mathrm{Cr})$ were measured by oxidase methods; homocysteine (HCY) was enzymatically cycled, all the measurements were carried out in strict accordance with the instructions of the kit; estimated glomerular filtration rate (eGFR) was simplified MDRD formula calculation: eGFR $\left[\mathrm{mL} /\left(\min \cdot 1.73 \mathrm{~m}^{2}\right)\right]=186 \times(\mathrm{Cr} / 88.4)-$ $1.154 \times$ age $-0.203 \times 0.742$. Cardiac diastolic function parameters were measured by echocardiography (PHILIPS EPIQ-7C), and LV diastolic peak filling flow rate (Peak E), LV end-diastolic peak filling flow rate (Peak A) were recorded. Peak E/A ratio less than 1 was considered as LV diastolic dysfunction together with other measurements by agreements with two experienced ultrasonic consultants [14].

\section{Data analysis}

Statistical analysis was performed by using SPSS 21.0 statistical software (IBM ${ }^{\ominus}$ SPSS Statistics, New York, USA) and EmpowerStats (http://www.empowerstats. com, X\&Y Solutions, Inc., Boston, MA). Data were presented as mean \pm standard deviation (SD) or median (interquartile) for continuous variables, and as frequency or percentage for categorical variables. The $t$ tests and 
chi-square tests were used to determine any statistical difference between the means and proportions of the two groups. Single-factor analysis of variance was used for comparison between groups. Univariate and multiple logistic regression models were used to evaluate the associations between HbAlc levels, the BMI, and LV diastolic dysfunction. Both non-adjusted and multivariate adjusted models (variables adjusted for age, sex, smoking status, drinking status, systolic blood pressure, diastolic blood pressure and course of disease, glomerular filtration rate, triglyceride and uric acid) were applied. Interaction and stratified analysis were conducted according to HbA1c levels (HbA1c $\geq 9 \% ; 7 \% \leq \mathrm{HbA} 1 \mathrm{c}<$ $9 \%, \quad \mathrm{HbA} 1 \mathrm{c}<7 \%)$ and BMI status $\left(\mathrm{BMI}<24 \mathrm{~kg} / \mathrm{m}^{2}\right.$; BMI $\geq 24 \mathrm{~kg} / \mathrm{m}^{2}$ ). Curve-fitting analysis was performed to further clarify the action trend of HbA1c levels and LV diastolic dysfunction in different BMI groups. A priori interactions between BMI and $\mathrm{HbAlc}$ using the multivariable Cox regression model was analysed to further assess whether the relationship between $\mathrm{HbA1c}$ and LV diastolic dysfunction varied by BMI status. $P$ value $<$ 0.05 was considered as statistically significant.

\section{Results}

\section{Subjects and clinical characteristics}

Among 925 patients with type 2 diabetes in this study, there were 391 cases with normal body weight $(\mathrm{BMI}<$
$24 \mathrm{~kg} / \mathrm{m}^{2}$ ), 534 cases with overweight/ obese (BMI $\geq 24$ $\mathrm{kg} / \mathrm{m}^{2}$ ). There were no significant differences in age, total cholesterol, high-density lipoprotein, low-density lipoprotein, eGFR, HbA1c levels between two groups $(P>0.05)$. Overweight/obese group had more smokers and alcohol drinkers than normal weight group (44.57\% vs $35.55,33.52 \%$ vs $21.23 \%$ respectively). Overweight/ obese patients had higher blood pressure, higher serum triglycerides, higher uric acid and 24-h urinary but lower high-density lipoprotein levels $(P<0.05)$. The proportion of LV diastolic dysfunction was higher in overweight/obese group (68.29\% vs $75.09 \%, P=0.0022)$. The ejection fraction (EF value) was not statistically significant between the two groups (Table 1).

We then compared the baseline characteristics of normal LV diastolic function group with LV diastolic dysfunction group. There were no significant differences in HbA1c level, triglyceride, total cholesterol, high-density lipoprotein, low-density lipoprotein, ejection fraction, drinking history, diastolic blood pressure between two groups $(P>0.05)$. The age of diastolic dysfunction group was older (mean age was $47.08 \pm 10.44$ years in the normal group and $59.17 \pm 10.77$ years in the dysfunction group; $P<0.001$ ), and the course of disease was longer $(7.68 \pm 6.24$ years in the normal group and $11.34 \pm 7.07$ years in the dysfunction group, $P<0.001$ ). Systolic blood pressure in LV diastolic dysfunction group was

Table 1 Clinical characteristics between normal weight group and overweight/obesity group in patients with type 2 diabetes

\begin{tabular}{|c|c|c|c|}
\hline Characteristic & Normal weight $N(\%) /$ Mean \pm SD & Overweight/Obese $N(\%) /$ Mean \pm SD & $P$ value \\
\hline Cases & 391 & 534 & \\
\hline Sex (male) & $247(63.17 \%)$ & $405(75.84 \%)$ & $<0.001 a$ \\
\hline Age (years) & $57.09 \pm 11.86$ & $57.61 \pm 11.67$ & $0.059 b$ \\
\hline Course of disease (years) & $10.81 \pm 7.13$ & $9.85 \pm 7.09$ & $0.035 b$ \\
\hline Smoking & 139 (35.55\%) & $238(44.57 \%)$ & $0.022 \mathrm{a}$ \\
\hline Alcohol drinking & $83(21.23 \%)$ & $179(33.52 \%)$ & $<0.001 a$ \\
\hline BMI $\left(\mathrm{kg} / \mathrm{m}^{2}\right)$ & $22.16 \pm 1.32$ & $26.79 \pm 2.15$ & $<0.001 \mathrm{~b}$ \\
\hline Systolic pressure (mmHg) & $127.12 \pm 20.16$ & $131.71 \pm 16.91$ & $<0.001 b$ \\
\hline Diastolic pressure $(\mathrm{mmHg})$ & $76.03 \pm 10.70$ & $79.48 \pm 10.10$ & $<0.001 b$ \\
\hline Triglyceride (mmol/L) & $1.76 \pm 0.86$ & $2.07 \pm 1.12$ & $<0.001 b$ \\
\hline Total cholesterol (mmol/L) & $4.34 \pm 1.12$ & $4.46 \pm 1.64$ & $0.232 b$ \\
\hline High-density lipoprotein (mmol/L) & $0.96 \pm 0.24$ & $0.98 \pm 0.21$ & $0.217 b$ \\
\hline Low-density lipoprotein (mmol/L) & $2.67 \pm 0.87$ & $2.66 \pm 0.90$ & $0.823 b$ \\
\hline Glycosylated hemoglobin(\%) & $8.86 \pm 2.10$ & $8.68 \pm 2.02$ & $0.185 b$ \\
\hline Uric acid (umol/L) & $345.80 \pm 83.39$ & $389.45 \pm 97.26$ & $<0.001 b$ \\
\hline $\mathrm{eGFR}\left(\mathrm{mL} / \mathrm{min} / 1.73 \mathrm{~m}^{2}\right)$ & $112.11 \pm 37.10$ & $111.79 \pm 54.13$ & $0.083 b$ \\
\hline 24-h urinary albumin (mg/24 h) & $97.78 \pm 346.39$ & $161.16 \pm 537.57$ & $<0.001 b$ \\
\hline Left ventricular diastolic dysfuction) & $267(68.29 \%)$ & $401(75.09 \%)$ & $0.022 \mathrm{a}$ \\
\hline Ejection fraction(\%) & $66.71 \pm 4.78$ & $66.38 \pm 4.78$ & $0.308 b$ \\
\hline
\end{tabular}

a: $P$ values of categorical variables were obtained by the chi-square test

b: $P$ values of continuous variables were obtained by student $t$ test 
higher in the dysfunction group (mean systolic blood pressure was $124.81 \pm 15.84 \mathrm{mmHg}$ in the normal group and $131.42 \pm 19.09 \mathrm{mmHg}$ in the dysfunction group; $P<0.001$ ), the systolic blood pressure was controlled within the normal range (Table 2).

\section{Regression analysis of BMI levels, HbA1c levels and LV diastolic dysfunction in patients with type 2 diabetes}

We applied logistic regression to analyze the BMI levels and LV diastolic dysfunction. We applied two models for the investigation: Non-adjusted model and adjusted model (with gender, age, smoking status, drinking status, systolic blood pressure, diastolic blood pressure and course of disease, glomerular filtration rate, triglyceride and uric acid). In general, we found BMI levels from patients with type 2 diabetes had associations with LV diastolic dysfunction in two models [non-adjusted model: 1.07 (1.02, 1.13), $P=0.0059$, adjusted model: 1.12 (1.05, 1.20), $P=0.0010)]$. Comparing with the normal weight group, the risk ratio (OR value) was 1.40 (1.05, 1.87), $P=0.087$ in overweight/obese group with non-adjusted model and was 1.71 (1.17, 2.50), $P=0.0056$ with adjusted model.

We then applied logistic regression to analyze the HbA1c levels and LV diastolic dysfunction with type 2 diabetes. There were not any association both in non-adjusted model $[0.95(0.89,1.02), P=0.1589]$ and adjusted model $[0.99(0.91,1.08), P=0.8601]$ (Table 3).
Stratified and curve fitting analysis of $\mathrm{HbA1c}$ and LV diastolic dysfunction in patients with type 2 diabetes To further explore whether the relationship between $\mathrm{HbA1c}$ and LV diastolic dysfunction in type 2 diabetes is affected by BMI, stratified analysis was performed (Table 4). We found that HbA1c was significantly associated with LV diastolic dysfunction in the normal weight group ( $\mathrm{OR}=1.14(1.01,1.30), P=0.0394)$, whereas not in overweight/obese group ( $\mathrm{OR}=0.92(0.82,1.03), P=0.1315$ ), suggesting that the association between $\mathrm{HbA1c}$ and left ventricular diastolic dysfunction is affected by BMI levels.

We further performed curve fitting analysis for the two BMI groups for LV diastolic dysfunction; the results were shown in Fig. 1. The relationships between HbA1c levels and LV diastolic dysfunction were different at different BMI state: in normal body weight group, HbA1C levels and LV diastolic function had a curve relationship, before the curve inflection point (about 10\%), the risk of LV diastolic dysfunction increased when HbA1C level increased, after the point, the HbA1c level did not affect LV diastolic dysfunction any more. In overweight/obesity group, the baseline risk of LV diastolic dysfunction in these patients is already high even if the level of HbA1c was low, and the HbA1c level was no longer a key factor to contribute the risk.

Interaction analysis of BMI, HbA1c levels on LV diastolic dysfunction in patients with type 2 diabetes

Interaction analysis revealed that there was a significant interaction between BMI and HbA1c level to affect LV

Table 2 Clinical characteristics between normal LV diastolic function and left ventricular diastolic dysfunction in patients with type 2 diabetes

\begin{tabular}{|c|c|c|c|}
\hline Characteristic & $\begin{array}{l}\text { Normal left ventricular diastolic } \\
\text { function } N(\%) / \text { Mean } \pm \text { SD }\end{array}$ & $\begin{array}{l}\text { Left ventricular diastolic } \\
\text { dysfunction } N(\%) / \text { Mean } \pm \text { SD }\end{array}$ & $P$ value \\
\hline Cases & $257(27.78 \%)$ & $668(72.22 \%)$ & \\
\hline Sex (male) & $190(71.43 \%)$ & $391(62.26 \%)$ & $0.009 a$ \\
\hline Age (years) & $47.08 \pm 10.44$ & $59.17 \pm 10.77$ & $<0.001 b$ \\
\hline Course of disease (years) & $7.68 \pm 6.24$ & $11.34 \pm 7.07$ & $<0.001 b$ \\
\hline Smoking & 117 (43.98\%) & 227 (36.15\%) & $0.028 a$ \\
\hline Alcohol drinking & 77 (28.95\%) & $154(24.52 \%)$ & $0.167 a$ \\
\hline Systolic pressure (mmHg) & $124.81 \pm 15.84$ & $131.42 \pm 19.09$ & $<0.001 b$ \\
\hline Diastolic pressure $(\mathrm{mmHg})$ & $78.34 \pm 9.87$ & $77.28 \pm 10.61$ & $0.163 b$ \\
\hline $\mathrm{HbA} 1 \mathrm{c}(\%)$ & $8.91 \pm 2.18$ & $8.67 \pm 1.95$ & $0.100 b$ \\
\hline Triglyceride (mmol/L) & $2.08 \pm 1.13$ & $2.06 \pm 1.14$ & $0.813 b$ \\
\hline $\begin{array}{l}\text { High-density lipoprotein } \\
\text { (mmol/L) }\end{array}$ & $0.97 \pm 0.23$ & $0.99 \pm 0.24$ & $0.551 b$ \\
\hline $\begin{array}{l}\text { Low-density lipoprotein } \\
(\mathrm{mmol} / \mathrm{L})\end{array}$ & $2.67 \pm 0.85$ & $2.55 \pm 0.93$ & $0.057 b$ \\
\hline BMI (kg/m2) & $24.23 \pm 3.03$ & $25.12 \pm 3.02$ & $<0.001 \mathrm{~b}$ \\
\hline Ejection fraction(\%) & $66.34 \pm 4.55$ & $66.82 \pm 4.80$ & $0.182 b$ \\
\hline
\end{tabular}

a: $P$ values of categorical variables were obtained by the chi-square test

b: $P$ values of continuous variables were obtained by student $t$ test 
Table 3 Logistic regression analysis of BMI, HbA1c and LV diastolic dysfunction in patients with type 2 diabetes

\begin{tabular}{|c|c|c|}
\hline Exposure & Non-adjusted model OR(95\% Cl) $P$ value & Adjusted model OR(95\% Cl) $P$ value \\
\hline $\begin{array}{l}\text { BMI (kg/m²) } \\
\text { (Analysis by continuous variables) }\end{array}$ & $1.07(1.02,1.13) 0.0059$ & $1.12(1.05,1.20) 0.0010$ \\
\hline \multicolumn{3}{|c|}{$\mathrm{BMI}\left(\mathrm{kg} / \mathrm{m}^{2}\right.$ ) (Analysis by categorical variables) } \\
\hline $\mathrm{BMI}<24\left(\mathrm{~kg} / \mathrm{m}^{2}\right)$ & 1.0 (ref.) & 1.0(ref.) \\
\hline $\mathrm{BMI} \geq 24\left(\mathrm{~kg} / \mathrm{m}^{2}\right)$ & $1.40(1.05,1.87) 0.0227$ & $1.71(1.17,2.50) 0.0056$ \\
\hline $\begin{array}{l}\text { HbA1c(\%) } \\
\text { (Analysis by continuous variables) }\end{array}$ & $0.95(0.89,1.02) 0.1589$ & $0.99(0.91,1.08) 0.8601$ \\
\hline \multicolumn{3}{|c|}{ HbA1c (Analysis by categorical variables) } \\
\hline $\mathrm{HbA} 1 \mathrm{c}<7 \%$ & 1.0(ref.) & 1.0(ref.) \\
\hline $7 \% \leq \mathrm{HbA} 1 \mathrm{C}<9 \%$ & $1.07(0.72,1.60) 0.7210$ & $0.90(0.56,1.47) 0.6855$ \\
\hline $\mathrm{HbA} 1 \mathrm{c} \geq 9 \%$ & $0.82(0.55,1.20) 0.3043$ & $1.03(0.63,1.67) 0.9120$ \\
\hline
\end{tabular}

Adjusted model: adjusted for age, sex, smoking status, drinking status, systolic blood pressure, diastolic blood pressure and course of disease, glomerular filtration rate,triglyceride and uric acid

$O R$ Odds ratio, $\mathrm{Cl}$ Confidence interval

diastolic function $(P=0.0371)$. The results were shown in Table 5. We then applied multivariable Cox regression to assess the role of each subgroup model combination in LV diastolic dysfunction. We took subgroup model combining normal body weight $\left(B M I<24 \mathrm{~kg} / \mathrm{m}^{2}\right)$ with $\mathrm{HbA} 1 \mathrm{c}<7 \%$ as the reference. The results were shown in Fig. 2. In the normal weight group, the risk of LV diastolic dysfunction presented an U-shaped curve as the increase of HbA1c level the ORs in $\mathrm{HbA} 1 \mathrm{c} \geq 9 \%$, $7 \% \leq \mathrm{HbA} 1 \mathrm{c}<9 \%$ and $\mathrm{HbA} 1 \mathrm{c}<7 \%$ group were 1.62 , $0.82,1$ respectively, which was consistent with previous study [8]. In the overweight/obese group, no positive correlation was found. The combination of overweight/ obese group and $\mathrm{HbA} 1 \mathrm{c}<7 \%$ had the greatest risk of $\mathrm{LV}$ diastolic dysfunction $[\mathrm{OR}=2.50(1.11,5.62), P=0.0271]$. It may suggest that $\mathrm{HbA} 1 \mathrm{c}<7 \%$ is no longer the optimal control threshold in the management of cardiovascular complications in overweight/obese patients.

\section{Discussion}

The incidence of type 2 diabetes has rapidly increased over recent decades and become one of leading public health problems in China. One third of patients with heart failure have diabetes. This is partly because all the

Table 4 Stratified analysis of $\mathrm{HbA} 1 \mathrm{C}$ and LV diastolic dysfunction in patients with type 2 diabetes

\begin{tabular}{lll}
\hline Exposure & $\begin{array}{l}\mathrm{BMl}<24 \mathrm{~kg} / \mathrm{m}^{2} \\
\mathrm{OR}(95 \% \mathrm{Cl}) P \text { value }\end{array}$ & $\begin{array}{l}\mathrm{BMI} \geq 24 \mathrm{~kg} / \mathrm{m}^{2} \\
\mathrm{OR}(95 \% \mathrm{Cl}) P \text { value }\end{array}$ \\
\hline HbA1c(\%) & $1.14(1.01,1.30) 0.0394$ & $0.92(0.82,1.03) 0.1315$ \\
$\mathrm{HbA1c}$ & & \\
$\mathrm{HbA} 1 \mathrm{C}<7 \%$ & 1.0 (Ref.) & 1.0 (Ref.) \\
$7 \% \leq \mathrm{HbA} 1 \mathrm{C}<9 \%$ & $0.71(0.35,1.47) 0.3632$ & $0.97(0.52,1.82) 0.9356$ \\
HbA1c $\geq 9 \%$ & $1.86(0.90,3.82) 0.0928$ & $0.71(0.39,1.31) 0.2765$ \\
\hline
\end{tabular}

OR Odds ratio, $\mathrm{Cl}$ Confidence interval, Ref Reference major risk factors for heart failure can present in patients with type 2 diabetes such as obesity, hypertension, advanced age, sleep apnoea, dyslipidaemia, anemia, chronic kidney disease, and coronary heart disease [15]. Hyperglycaemia is a risk factor for heart failure in persons with type 2 diabetes [16]. Excess body weight, is also a major risk factor for cardiovascular disease [17].

Understanding the relationships between BMI levels, HbA1c levels and LV diastolic dysfunction in the patients with type 2 diabetes will help clinicians to have appropriate management plans for the patients and reduce heart failure rates in patients. In this investigation, we had an in-depth analysis of the relationships among BMI, HbA1c and LV diastolic dysfunction of 925 type 2 diabetes patients in South China. We had found that the BMI was an independent risk factor to LV diastolic dysfunction, confirming previous reports from South Korea [18], Australia and the Netherlands [19], and USA [20]. Chinese population was transformed from one of the leanest populations to have more than 200 million overweight or obese in its population [21]. Our results of the independent role of BMI to LV diastolic dysfunction in type 2 diabetes indicates the importance of education of health diets, exercises to prevent the most common heart diseases in China.

Hyperglycaemia has detrimental effects on the myocardium [5]. It up-regulates renin-angiotensin-aldosterone system, increases oxidative stress [22], promotes accumulation of glycation end-products and causes interstitial fibrosis in heart muscle [23]. Hyperglycaemia has strong associations with myocardial lipotoxicity, mitochondrial dysfunction, abnormal substrate metabolism and impaired calcium handling [6]. The HbA1c level is now recommended as a standard for testing and monitoring diabetes [24]. Previous investigations from DCCT, ADVANCE and UKPDS showed that the risk of microangiopathy in 


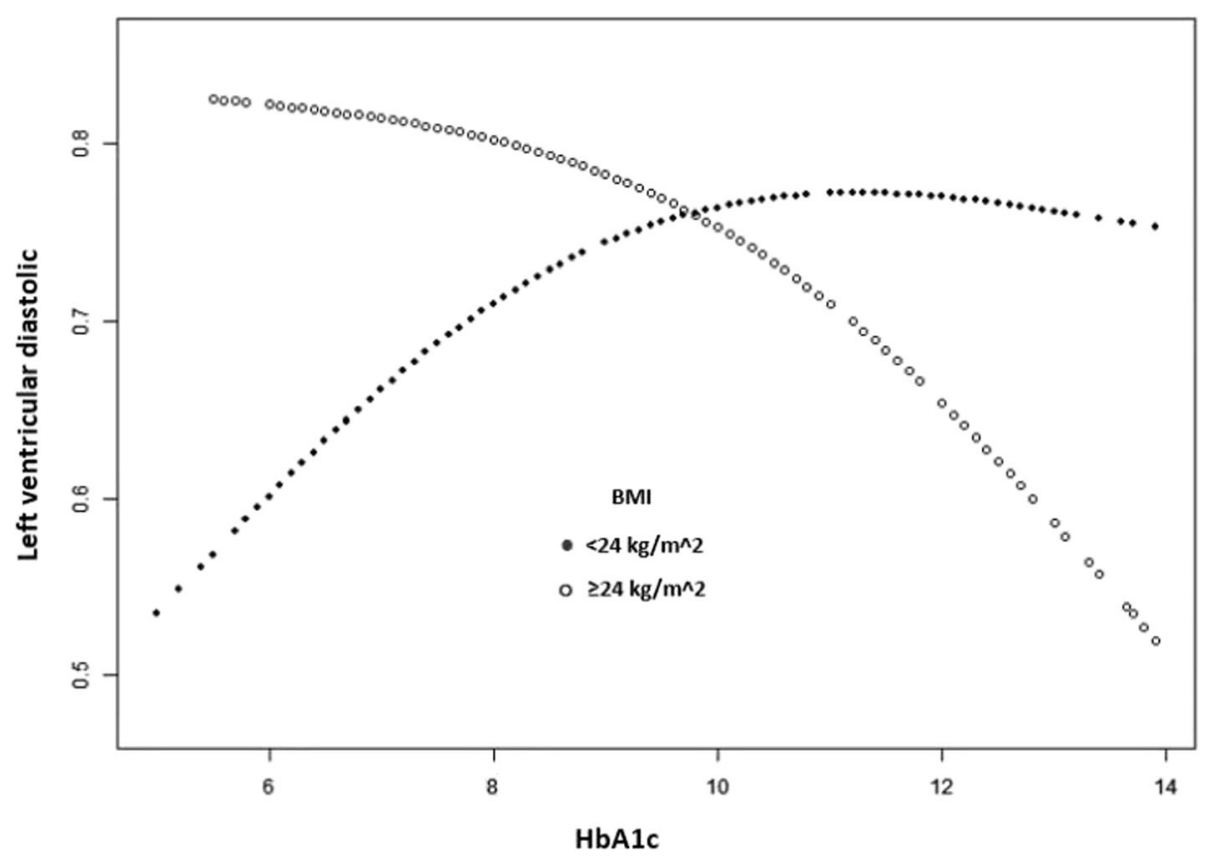

Fig. 1 Relationship between HbA1c and LV diastolic dysfunction in patients with type 2 diabetes at different BMl states. Curve fitting analysis was performed in the two BMI groups for LV diastolic dysfunction. $y$-axes: Left diastolic function; $x$-axes: HbA1C levels

patients with type 2 diabetes increased with the increase of HbA1c levels. The microangiopathy in these studies were mostly diabetic nephropathy, diabetic retinopathy and neuropathy [25-27]. The relationship between HbA1c and LV diastolic dysfunction has been reported as contradiction. Giorda et al. found that HbA1c was significantly correlated with LV diastolic function in patients with type 2 diabetes [28], Clarke et al. also found that LV diastolic dysfunction is inversely linked to glycemic control in T2DM patients [29]. Noh et al. did not found that HbA1c increased risk of LV diastolic dysfunction in type 2 diabetes [30]. The different results may be related to the different blood glucose control status of the included populations. In our present study, we did not found significant correlation between HbA1c level and LV diastolic

Table 5 Interaction Analysis of the BMI and $\mathrm{HbA1C}$ in LV diastolic dysfunction in patient with type 2 diabetes

\begin{tabular}{lll}
\hline Exposure & HbA1c level & OR $(95 \% \mathrm{Cl}) P$ value \\
\hline $\mathrm{BMI}<24\left(\mathrm{~kg} / \mathrm{m}^{2}\right)$ & $\mathrm{HbA} 1 \mathrm{c}<7 \%$ & Ref. \\
$\mathrm{BMI} \geq 24\left(\mathrm{~kg} / \mathrm{m}^{2}\right)$ & $\mathrm{HbA} 1 \mathrm{c}<7 \%$ & $2.50(1.11,5.62) 0.0176$ \\
$\mathrm{BMl}<24\left(\mathrm{~kg} / \mathrm{m}^{2}\right)$ & $7 \% \leq \mathrm{HbA} 1 \mathrm{c}<9 \%$ & $0.83(0.42,1.62) 0.5782$ \\
$\mathrm{BMI} \geq 24\left(\mathrm{~kg} / \mathrm{m}^{2}\right)$ & $7 \% \leq \mathrm{HbA} 1 \mathrm{c}<9 \%$ & $2.15(1.09,4.21) 0.0262$ \\
$\mathrm{BMl}<24\left(\mathrm{~kg} / \mathrm{m}^{2}\right)$ & $\mathrm{HbA} 1 \mathrm{c} \geq 9 \%$ & $1.62(0.83,3.15) 0.158$ \\
$\mathrm{BMI} \geq 24\left(\mathrm{~kg} / \mathrm{m}^{2}\right)$ & $\mathrm{HbA} 1 \mathrm{C} \geq 9 \%$ & $1.65(0.84,3.24) 0.1443$ \\
$P$ interaction & & 0.0371
\end{tabular}

OR Odds ratio, $\mathrm{Cl}$ Confidence interval, Ref Reference. $P$ interaction: $P$ value was calculated for comparison between subgroups dysfunction in patients with type 2 diabetes. Our results suggest that HbA1c effects on LV diastolic dysfunction may be affected by some other confounding factors. Obesity is becoming increasingly prominent, not only affecting cardiovascular health, but also leading to glucose and lipid metabolism disorder. Stratified analysis in our investigation found that HbA1c was statistically correlated with LV diastolic dysfunction only in the normal weight group, suggesting that obesity is an important confounding factor in the relationship between HbA1c and LV diastolic dysfunction. In the normal weight group, we found that the relationship between $\mathrm{HbA1c}$ and LV diastolic dysfunction was curvilinear correlation, and had a saturation threshold (10\%). In a Scotland cohort study of 8683 patients with type 2 diabetes, both high and low HbA1c levels have been found to predict heart failure development forming a Ushaped relationship [8]. It may suggest that under normal weight, proper glycemic control is beneficial to the improvement of heart function. When HbA1c is higher than a certain range (10\%) or in overweight/obesity, glycemic control may no longer be the most important factor affecting LV diastolic dysfunction. More attention should be paid to the some other effects such as lipotoxicity on cardiac function. In a Western Indian study, the dyslipidemic obese subjects had significant linear association with HbA1c in type 2 diabetes subjects [31]. A rise in obesity and dyslipidemia with increasing urbanization have led to various lifestyle related disorders like type 2 diabetes, cardiovascular disease (CVD) and metabolic syndrome. Among dyslipidemic subjects, increased LDL-C, TG and 
$\mathrm{HbA} 1 \mathrm{c} \geq 10 \%$

$1.65(0.84,3.24)$

$1.62(0.83,3.15)$

$7 \% \leq \mathrm{HbA} 1 \mathrm{c}<10 \%$

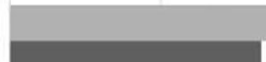

$0.83(0.42,1.62$

$2.15(1.09,4.21)$

$\mathrm{HbA} 1 \mathrm{c}<7 \%$

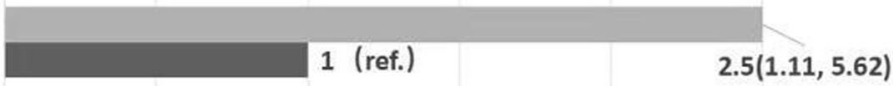

\begin{tabular}{|c|c|c|c|}
\hline 0 & 0.5 & 1.5 & 2.5 \\
\hline & $\mathrm{HbA} 1 \mathrm{c}<7 \%$ & $7 \% \leq \mathrm{HbA} 1 \mathrm{c}<10 \%$ & $H b A 1 c \geq 10 \%$ \\
\hline$=\mathrm{BMI} \geq 24 \mathrm{~kg} / \mathrm{m}^{\wedge} 2$ & 2.5 & 2.15 & 1.65 \\
\hline BMI $<24 \mathrm{~kg} / \mathrm{m}^{\wedge} 2$ & 1 & 0.83 & 1.62 \\
\hline
\end{tabular}

Fig. $2 \mathrm{BMI}$ and HbA1c subgroup and LV diastolic dysfunction in patients with type 2 diabetes. Multivariable Cox regression model to assess the role of each subgroup model combination in left ventricular diastolic dysfunction. A subgroup model combining normal body weight (BMl $<24$ $\mathrm{kg} / \mathrm{m}^{2}$ ) with $\mathrm{HbA} 1 \mathrm{c}<7 \%$ was used as a reference

hypo-HDL are established markers for CAD risk. The other reason is that HbA1c-lowering is greater in populations with poor glycaemic control than in well controlled populations with the same degree of weight loss [32]. The genetic background for type 2 diabetes may be different in South China and may be relevance to the complex phenotypes of HbA1c phenotypes of patients with type 2 diabetes. In overweight/obese group, analysis found the obesity paradox: increased HbA1c unexpectedly reduced the risk of diastolic dysfunction, which was similar to some previous obesity paradox studies [33-35]. There may be some other unmeasured confounders not yet be excluded, or because obesity itself may be a risk factor for disease events, and stratification bias can amplify the effects of confounding factors. The specific causes still need to be further investigated.

In this study, it was found for the first time that BMI and $\mathrm{HbA1C}$ had significant interactions in influencing the left ventricular diastolic dysfunction, suggesting that the interaction of multiple factors should be considered in the management of cardiac complications in type 2 diabetes mellitus.

There were some limitations in this study. The current investigation applied the evaluation index using the E/A ratio in the echocardiogram, it did not investigate the state of the heart load; the HbA1c levels which represented glycemic control in this study, only corresponded to changes in blood glucose levels for nearly 3 months, while diabetes cardiomyopathy and obesity are metabolic diseases and the pathological processes that change gradually over a long period of time. Single HbA1c may not reflect the historical impact of hyperglycemia on diastolic dysfunction. The effects of some medications and other confounders such as blood pressure and blood lipids were not fully considered, these confounders are needed to further research in detail.

The current investigation provides clinical implication about the importance of weight control in patients with type 2 diabetes as higher BMI was clearly a risk of LV diastolic dysfunction. It also indicates monitoring both HbA1c levels and BMI levels could assist us for correctly predicting early heart function changes for the patients. The results can help clinicians for appropriate management of patients with type 2 diabetes.

\section{Conclusions}

In patients with type 2 diabetes, the correlation between LV diastolic dysfunction and HbA1c was interactively affected by BMI levels. Under normal body weight, proper glycemic control is beneficial to protect the heart function when HbA1c is less than $10 \%$, Under overweight/obese condition, the risk of LV diastolic dysfunction in these patients may not related to the HbA1c level, indicating weight loss could bring cardiovascular benefits in the patients with type 2 diabetes.

\section{Availability of data and materials}

The experimental datasets in the analysis described in this study are available from Professor Dewen Yan or Dr. Xin Zuo.

\section{Abbreviations}

BMI: Body mass index; CVD: Cardiovascular disease; DCM: Diabetic cardiomyopathy; EF: Ejection fraction; eGFR: Estimated glomerular filtration rate; HbA1c: Hemoglobin A1c or glycosylated hemoglobin; HDL-C: High Density lipoprotein cholesterol; LDL-C: Low density lipoprotein cholesterol; LV: Left ventricular; TG: Triglyceride 


\section{Acknowledgements}

We thank our colleagues who provided assistance in Xiangya-Shenzhen Endocrinology and Metabolism Center in the Department of Endocrinology at the First Affiliated Hospital of Shenzhen University. We are grateful the supports from Shenzhen Science and Technology Innovation Commission and National Natural Science Foundation of China. YZ is an Asmarley Lecturer in National Heart and Lung Institute at Imperial College London.

\section{Authors' contributions}

$X Z, Y Z$ and DY planned the overall study. XZ designed individual experimental components with advice from XL. XZ performed all the experimental work. $X Z$ and $X L$ analyzed measurements with assistance with RC, $H O$ and JL. XZ and DY carried out statistical analyses of the data with input from YZ. XZ, DY and YZ wrote the first draft of the paper. All authors have read and approved the manuscript.

\section{Funding}

This work was funded by Shenzhen Science and Technology Innovation Commission, the project number was JSGG20160331103247408. It was also funded by National Natural Science Foundation of China, the project number was 81670759.

\section{Availability of data and materials}

The original data were recorded in our cohort database and are available if required.

\section{Ethics approval and consent to participate}

The study was approved by the Ethics Committee of the First Affiliated Hospital of Shenzhen University, Shenzhen, China and was performed in accordance with the approved guidelines and regulations. Informed written consent was obtained from the parents of all subjects.

\section{Consent for publication}

Not applicable.

\section{Competing interests}

The authors declare that they have no competing interests.

\section{Received: 18 April 2019 Accepted: 15 August 2019}

\section{Published online: 27 August 2019}

\section{References}

1. Zimmet P, Alberti KG, Shaw J. Global and societal implications of the diabetes epidemic. Nature. 2001;414(6865):782-7.

2. Zinman B, Wanner C, Lachin JM, Fitchett D, Bluhmki E, Hantel S, et al. Empagliflozin, cardiovascular outcomes, and mortality in type 2 Diabetes. $\mathrm{N}$ Engl J Med. 2015;373(22):2117-28.

3. Galderisi M. Diastolic dysfunction and diabetic cardiomyopathy: evaluation by Doppler echocardiography. J Am Coll Cardiol. 2006;48(8):1548-51.

4. Schannwell CM, Schneppenheim M, Perings S, Plehn G, Strauer BE. Left ventricular diastolic dysfunction as an early manifestation of diabetic cardiomyopathy. Cardiology. 2002;98(1-2):33-9.

5. Boudina S, Abel ED. Diabetic cardiomyopathy revisited. Circulation. 2007; 115(25):3213-23.

6. Zhou YT, Grayburn P, Karim A, Shimabukuro M, Higa M, Baetens D, et al. Lipotoxic heart disease in obese rats: implications for human obesity. Proc Natl Acad Sci U S A. 2000;97(4):1784-9.

7. Yan D, Luo X, Li Y, Liu W, Deng J, Zheng N, et al. Effects of advanced glycation end products on calcium handling in cardiomyocytes. Cardiology. 2014;129(2):75-83.

8. Parry HM, Deshmukh H, Levin D, Van Zuydam N, Elder DH, Morris AD, et al. Both high and low $\mathrm{HbA} 1 \mathrm{c}$ predict incident heart failure in type 2 diabetes mellitus. Circ Heart Fail. 2015;8(2):236-42.

9. Stratton IM, Adler Al, Neil HA, Matthews DR, Manley SE, Cull CA, et al. Association of glycaemia with macrovascular and microvascular complications of type 2 diabetes (UKPDS 35): prospective observational study. Bmj. 2000;321(7258):405-12.

10. Patil VC, Patil HV, Shah KB, Vasani JD, Shetty P. Diastolic dysfunction in asymptomatic type 2 diabetes mellitus with normal systolic function. $J$ Cardiovasc Dis Res. 2011;2(4):213-22.
11. Yach D, Stuckler D, Brownell KD. Epidemiologic and economic consequences of the global epidemics of obesity and diabetes. Nat Med. 2006;12(1):62-6.

12. American Diabetes A. (2) Classification and diagnosis of diabetes. Diabetes Care. 2015;38(Suppl):S8-S16.

13. Jensen MD, Ryan DH, Apovian CM, Ard JD, Comuzzie AG, Donato KA, et al. 2013 AHA/ACC/TOS guideline for the management of overweight and obesity in adults: a report of the American College of Cardiology/American Heart Association task force on practice guidelines and the Obesity Society. Circulation. 2014;129(25 Suppl 2):S102-38.

14. Chaudhary AK, Aneja GK, Shukla S, Razi SM. Study on diastolic dysfunction in newly diagnosed type 2 Diabetes mellitus and its correlation with glycosylated Haemoglobin (HbA1C). J Clin Diagn Res : JCDR. 2015;9(8): OC20-2.

15. Thomas MC. Type 2 Diabetes and heart failure: challenges and solutions. Curr Cardiol Rev. 2016;12(3):249-55.

16. Skrtic S, Cabrera C, Olsson M, Schnecke V, Lind M. Contemporary risk estimates of three $\mathrm{HbA1c}$ variables in relation to heart failure following diagnosis of type 2 diabetes. Heart. 2017;103(5):353-8.

17. Scherer PE, Hill JA. Obesity, Diabetes, and cardiovascular diseases: a compendium. Circ Res. 2016;118(11):1703-5.

18. Seo JS, Jin HY, Jang JS, Yang TH, Kim DK, Kim DS. The relationships between body mass index and left ventricular diastolic function in a structurally Normal heart with Normal ejection fraction. J Cardiovasc Ultrasound. 2017; 25(1):5-11.

19. Ng ACT, Prevedello F, Dolci G, Roos CJ, Djaberi R, Bertini M, et al. Impact of Diabetes and increasing body mass index category on left ventricular systolic and diastolic function. J Am Soc Echocardiogr : official publication of the American Society of Echocardiography. 2018;31(8):916-25.

20. Aljaroudi W, Halley C, Houghtaling P, Agarwal S, Menon V, Rodriguez L, et al. Impact of body mass index on diastolic function in patients with normal left ventricular ejection fraction. Nutr Diabetes. 2012;2:e39.

21. Wu Y. Overweight and obesity in China. Bmj. 2006;333(7564):362-3.

22. Cohn JN, Johnson G, Ziesche S, Cobb F, Francis G, Tristani F, et al. A comparison of enalapril with hydralazine-isosorbide dinitrate in the treatment of chronic congestive heart failure. N Engl J Med. 1991;325(5): 303-10.

23. Miki T, Yuda S, Kouzu H, Miura T. Diabetic cardiomyopathy: pathophysiology and clinical features. Heart Fail Rev. 2013;18(2):149-66.

24. American Diabetes A. 6. Glycemic targets: standards of medical Care in Diabetes-2018. Diabetes Care. 2018:41(Suppl 1):S55-64.

25. Skyler JS. Diabetic complications. The importance of glucose control. Endocrinol Metab Clin N Am. 1996;25(2):243-54.

26. Holman RR, Paul SK, Bethel MA, Matthews DR, Neil HA. 10-year follow-up of intensive glucose control in type 2 diabetes. N Engl J Med. 2008;359(15):1577-89.

27. Diabetes C, Complications Trial Research G, Nathan DM, Genuth S, Lachin J, Cleary $P$, et al. The effect of intensive treatment of diabetes on the development and progression of long-term complications in insulindependent diabetes mellitus. N Engl J Med. 1993;329(14):977-86.

28. Giorda CB, Cioffi G, de Simone G, Di Lenarda A, Faggiano P, Latini R, et al. Predictors of early-stage left ventricular dysfunction in type 2 diabetes: results of DYDA study. Eur J Cardiovasc Prev Rehab : official journal of the European Society of Cardiology, Working Groups on Epidemiology \& Prevention and Cardiac Rehabilitation and Exercise Physiology. 2011;18(3): 415-23.

29. Clarke GD, Molina-Wilkins M, Solis-Herrera C, Mendez V, Monroy A,

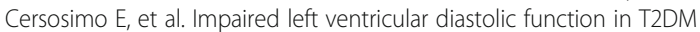
patients is closely related to glycemic control. Endocrinol Diabetes Metab. 2018:1(2):e00014.

30. Noh JH, Doh JH, Lee SY, Kim TN, Lee H, Song HY, et al. Risk factors associated with left ventricular diastolic dysfunction in type 2 diabetic patients without hypertension. Korean Diabetes J. 2010:34(1):40-6.

31. Sheth J, Shah A, Sheth F, Trivedi S, Nabar N, Shah N, et al. The association of dyslipidemia and obesity with glycated hemoglobin. Clin Diabetes Endocrinol. 2015;1:6

32. Gummesson A, Nyman E, Knutsson M, Karpefors M. Effect of weight reduction on glycated haemoglobin in weight loss trials in patients with type 2 diabetes. Diabetes Obes Metab. 2017;19(9):1295-305.

33. Carnethon MR, De Chavez PJ, Biggs ML, Lewis CE, Pankow JS, Bertoni AG, et al. Association of weight status with mortality in adults with incident diabetes. Jama. 2012;308(6):581-90. 
34. Badrick E, Sperrin M, Buchan IE, Renehan AG. Obesity paradox and mortality in adults with and without incident type 2 diabetes: a matched populationlevel cohort study. BMJ Open Diabetes Res Care. 2017;5(1):e000369.

35. Zhao W, Katzmarzyk PT, Horswell R, Wang Y, Li W, Johnson J, et al. Body mass index and the risk of all-cause mortality among patients with type 2 diabetes mellitus. Circulation. 2014;130(24):2143-51.

\section{Publisher's Note}

Springer Nature remains neutral with regard to jurisdictional claims in published maps and institutional affiliations.

Ready to submit your research? Choose BMC and benefit from:

- fast, convenient online submission

- thorough peer review by experienced researchers in your field

- rapid publication on acceptance

- support for research data, including large and complex data types

- gold Open Access which fosters wider collaboration and increased citations

- maximum visibility for your research: over $100 \mathrm{M}$ website views per year

At $\mathrm{BMC}$, research is always in progress.

Learn more biomedcentral.com/submissions 